\title{
The Influence of Technology, Environment and User Acceptance on the Effectiveness of Information System Project Selection Using SEM
}

\author{
Syaifudin ${ }^{1}$, Che Sobry Abdullah², Zulkifli Mohamed Udin ${ }^{2}$, Mohamad Ghozali bin \\ Hassan $^{2}$ and Nor Azmi Johari ${ }^{3}$ \\ ${ }^{1}$ Trisakti University, Jakarta, Indonesia \\ ${ }^{2}$ University Utara Malaysia, Sintok, Malaysia \\ ${ }^{3}$ Communication \& Entrepreneurship Center, UniMAP, Kangar, Malaysia
}

Received 19 April 2011; Accepted 2 June 2012; Published 30 December 2012

Academic Editor: Hana Klcova

\begin{abstract}
The selection of the present information system project is difficult because of the many factors that influence it. Information system project should pay attention to the user acceptance, technology and the environment in terms of their influence on the information system project selection. The purpose of this paper is to determine how much influence user acceptance, technology and the environment have on the information system project selection. This research uses data obtained from several ministries and analyzed using SEM (Structural Equation Models). The results found that the technology and the environment affects user acceptance. Moreover, technology and environment affect the effectiveness of the information systems project selection through the mediating effect of user acceptance. User acceptance, tested by the incorporation of usefulness and ease of use, the results are more modest and in line with previous theories. Furthermore, the external environment highly impacts the information system project selection.
\end{abstract}

Keywords: User acceptance, environment, technology, mediator, information system project.

\section{Introduction}

A challenge that must be faced in the information system project selection is the determination of the factors impacting it as this can effectively help organizations understand the system information on the overall organizational strategy, and use it to achieve business goals. Information systems project selection puts the business in a better position to assess the potential of information systems project and the sharing of effective resource allocation (Jiang \& Klein, 1999). More and more states or modern organizations rely on information systems for their daily business. The effective selection of the appropriate information system project will provide a competitive advantage. However, because the environment is complex, owing to the existence of factors such as; lack of funds and the dynamic situations of high uncertainty, the information system project selection may get complicated. Selection of appropriate information system projects is therefore a complex problem and requires an evaluation process through the

Copyright (C) 2013 Syaifudin, Che Sobry Abdullah, Zulkifli Mohamed Udin, Mohamad Ghozali bin Hassan and Nor Azmi Johari. This is an open access article distributed under the Creative Commons Attribution License unported 3.0, which permits unrestricted use, distribution, and reproduction in any medium, provided that original work is properly cited. Contact author: Syaifudin E-mail: fudin178@yahoo.com 
consideration of requirements (Ghasemzadeh \& Archer, 2000; Huang et al. (2008).

Many methods are used for selecting information systems projects including sorting, mathematical optimization and multi-criteria analysis. There is a shortage of using a score, rank or mathematical optimization in information systems project selection as a sophisticated mathematical model is difficult to understand (Puthamont and Charoenngen, 2007). The process of decision-making information systems project selection usually depends on several factors. Information system project selection can be seen as a problem of multi-criteria decision-making (Jiang \& Klein, 1999).

Jiang (1999) said that the selection of information system project is affected by the financial, environmental, technology, risk, organizational and management support. However, user acceptance was not examined. Davis (1998) said that an application should pay attention to user acceptance of information as measured by the perceived usefulness and perceived ease of use separately. So in this research, the impact of technology, environment and user acceptance upon information systems project selection is studied. To facilitate user acceptance study the perceived usefulness and perceived ease of use need to be combined. Additionally, it examines whether the project will affect the selection of information systems through user acceptance.

\section{The Effectiveness of the Information System Project Selection}

If an organization is successful in selecting information system project, it will pave the way for success in other fields. If the project fails then there is no motivation to use the system. The technology is expected to be accepted and a successful implementation of the user is also expected (Cohen \& Bailey, 1997). Implementing project selection will be satisfied if it conforms to the targets or regulatory means of effective selection (Bowman, 2006) and likewise, if the selection model or specific software to meet the user's goal or satisfaction is effective. If the model implements the specific software selection projects at a faster rate, it said to be efficient. The effectiveness of decision support in the selection of the project leads to the improvement of quality (Meade \& Presley, 2002; Zhang, Ghorbani \& Cohen, 2007) and with quality, there will be added value to the decision. The factors affecting the quality of project selection include: technology, economics, organization and environment. The weight of each factor depends on the decision maker. Effective is described by Gashemzadeh \& Archer (2000) as more usable, better, the existence of interdependence between the project and it leads to user satisfaction.

The selection of the project is said to be effective if the project is successful (Fedor et al., 2003; Hasan \& Ali, 2007). The dimensions of successful projects involves several items; rules to be followed during the project, desire towards project fulfillment, decision that satisfies the project, well-performance, and outcomes that exceed expectations (Fedor et al., 2003). Fedor stated that the impact of expected dimensions was studied in light of profitable projects, as it can be a valuable resource. A collection of the results of a successful project has widespread benefit. Based on Cohen and Bailey (1997), the effectiveness of merit, quantity, quality, and productivity may be assessed while Hasan (2007) says that the effectiveness of the selection of the projects is revealed through quality results, and satisfactory results. In an organization there are 5 effective gauges/measurements of successful projects; if the project is within budget, on schedule execution, characterized by innovation, project quality and efficiency (Cohen \& Bailey, 1997). Therefore, consistent with the study of information systems before (Fedor et al., 2003), this attempts to test the effectiveness of project success and its impact.

\section{Information Technology}

Information technology is a technology that helps people to create, modify, store, 
communicate or disseminate information. Information technology is an increasingly growing system. If someone does not want to miss the benefits of technology, they should learn how to use it. Each company is always developing information technology. Since the number of new information technologies is increasing, the prices are decreasing.

Technology is revealed to affect the selection of information system project (Yap, Ram \& Leong, 1992). In his research using technology SMART (Simple MultiAttribute Rating Technique), he revealed that the selection of projects will be easier with technology and it also leads to satisfying decisions. Furthermore, Hasan \& Ali (2007) examines a company's competitive advantage in light of project information system selection. The examination of the financial measures for several years and the results revealed that technology affects information system project selection. In another study, Chen (2009) examines the information system project selection with many factors such as, business goals, benefits, risks of the project and the limited resources available. His study used the method of multi-criteria decision-making (MCDM) to select a project information system based on fuzzy measurements. The result showed that an MCDM technology was found to be practical and useful in the selection of information system projects. Moreover, Lam's (2010) study involved the integration of large amounts of information systems to support business initiatives such as e-business, supply chain management and customer relationship management. The results revealed that information technology influence information system project selection.

Current technology is constantly influencing the interaction of individuals and society. For businesses, the growing amount of information that must be managed led to increased integration and system complexity. This leads to the skills required by users and the variables that affect user acceptance of information systems (Youngberg, 2009). Ghobakhloo (2010) in her study of user acceptance of technology in small and medium enterprises (SMEs), found that user acceptance of the technology influences small and medium businesses' use of technology for development. Liu (2010), on the other hand, examines the community through mobile entertainment. The results reveal that technology and quality service affect user acceptance. Furthermore, according to Jiang (2002), user satisfaction in information systems depends on the technology used.

\section{Environment}

The neighborhood is a combination of physical conditions that include the state of the resource. Environmental information system project is twofold - internal and external. Internal effects are inside the organization while external influences are from outside the organization. In organizational theory, the environment has long been thought to play an important role in the organizational structure of the relationship. Turbulent environment can encourage companies to be more knowledgeable in the use of information systems (Jiang \& Klein, 1999).

In Wei's (2007) study, the effect of environment on project selection was examined. The environment is considered in any decision-making. In addition, environmental decision-making should be considered in light of the strategic goals of the organization. Furthermore, Chen (2009) examined the information system project selection that takes place if the information is incomplete, vague and uncertain. In his study, he presented methods of multi-criteria decision making. The results showed the influence of the above factors upon the selection of information system projects. In a related study, Wang (2009) examined the construction projects in China in terms of environment of the region and compared it with other regions providing different protection. So owing to the different decision-making adopted by management, the local environmental decision-making of the organization influences the projects. Moreover, Rosaker \& Olson (2008) examined the selection of projects in the 
states of the United States. Each state has individual policy to support project selection decisions and hence, each impacts the state's information system project selection.

In any institution or region, if a company is desirous of building a project, then it should look at both internal and external institutional environment (Jiang \& Klein, 1999; Meade \& Presley, 2002). It should also see to the safety of the environment (Huang et al., 2008), if society has a negative impact, the project may stop running or it may not be selected. Therefore, a proposed feasible study is required according to the specified regulations or standards both nationally and internationally (Buchanan \& Vanderpooten, 2007).

The affect of the user's computing environment involves the implementation of applications, computational science and computing systems of the users (Yoon, 2009). Ghobakhloo (2010) in her study of user acceptance of technology in small and medium enterprises (SMEs) revealed that user acceptance is influenced by the environment. In addition, user acceptance and user satisfaction should be considered as both impact the success of the use of technology in small and medium businesses. The study shed a light on user acceptance of information technology and user satisfaction in SMEs with a focus on the environment as well as interaction between individuals within the organization and external to the organization. Liu (2010) in her study of user acceptance in the enterprise resource planning (ERP) in China, showed that family, friends and even work environment greatly affects user acceptance. Furthermore, Youngberg (2009) examines the use of technology in the company's employees and revealed that the organization affect the use of technology for the company's success.

\section{User Acceptance}

Information technology cannot provide increased effectiveness of the organization if it is not accepted and used by the user.
One of the tools to assess and predict user acceptance of information technology that has gained popularity in recent years is the technology acceptance model (TAM). As for the factors predicting user acceptance they are perceived usefulness and ease of use (Davis, 1989; Igbaria, Guimaraes \& Davis, 1995). In Igbaria's (1995) study, the determinants of the use of micro-computer through a structural equation model can declare variables affecting the technology, the organization, and the character of the user. The results of this study demonstrate the utility of external factors that contribute to the use of micro computers and other endogenous variables, such as those proposed by Davis (1989). Furthermore, Igbaria (1997) in her study of user acceptance, highlighted external variables that influence user acceptance namely technological, economic, organizational, cultural, environmental factors.

User acceptance is closely linked to the effectiveness of the information system project selection. To implement the project, user acceptance information should be considered. Ghobakhloo (2010), in her study of user acceptance of technology in small and medium enterprises (SMEs), stressed the affects the success of the use of technology in small and medium businesses. Understanding user acceptance of information technology and user satisfaction in SMEs with a special focus on the environment and the interactions required between individuals within the organization and with external organizations is very essential.

Furthermore, Zhou (2008) examined the use of mobile phones to spread entertainment to the community. He stated that user acceptance affect the successful project implementation in terms of information dissemination through mobile entertainment community. In addition, Youngberg's (2009) study on user acceptance of the technology showed that a company having users who accept and use technology is successful indicating the impact of user acceptance of information systems. 
Information system projects that run should pay attention to user acceptance. Information technology cannot provide an increase in the effectiveness of the organization if it is not accepted and used by the user. One of the tools to assess and predict user acceptance of information technology that has gained popularity in recent years is the technology acceptance model (TAM). As for the factors predicting user acceptance, they are perceived Usefulness, and Ease of use and the two should not be mixed (Davis, 1989; Igbaria, Guimaraes \& Davis, 1995). In addition, Davis (1989) states that external factors affect project information through the mediating effect of user acceptance. In a study of Venkatesh (2000) regarding the implementation of user acceptance of information, the results revealed the influence of external variables on user intention through the mediating effect of technology user acceptance where user acceptance is measured by Usefulness and Ease of use. Furthermore, Igbaria (1997) examined the factors affecting the use of personal computer at a small company in New Zealand. The results of the study revealed that external factors affect project information by the mediating role of user acceptance.

\section{Framework and Hypotheses}

The framework of the present study is adapted from Davis (1989), Iqbaria et al. (1997) and Jiang (1999). Davis (1989) stated that the project should pay attention to user acceptance of information while Davis stated, in TAM (technology has acceptance model), user acceptance is determined by the value of usefulness and ease of use examined separately, and it is interesting to study if combined. Additionally, user acceptance is influenced by external factors while external factors affect the project information through mediating role of user acceptance. Igbaria (1997) stated that outside factors: economics, technology and organization influence user acceptance and project information. Meanwhile, Yan (2006) stated that external factors include economy, culture and technology. Therefore, the external factors of TAM may be technological, economic and environmental. An empirical study by Jiang (1999) regarding the decision support for information system project selection used the statistical tests of MANOVA. The study findings revealed that the factors affecting the selection of information system project is technological, economic, environmental, and organizational risk.

Based on the description above and adopting the findings of studies that the effectiveness of the information systems project selection is influenced by technology, environment and user acceptance, user acceptance testing was performed by the incorporation of usefulness and ease of use with the mediating effect of user acceptance of the technology and the effectiveness of the information system project selection.

The hypotheses obtained from the study framework are as follows:

1. Technology affects the information systems project selection.

2. Environment influences the selection of information system project.

3. User acceptance affects information systems project selection.

4. Technology affects user acceptance.

5. Environment affects user acceptance.

6. Technology indirectly influences the selection of information system project through mediating effect of user acceptance.

7. Environment indirectly affects information systems project selection through mediating user acceptance.

\section{Methodology}

The methodology explains the detailed process of the research steps taken. The research method is a technique of investigation. Hair (2010) stated that the method of study sample consisted of data collection and the analysis to assess the 
accuracy of the results. Because the items were adopted and adapted from previous research, the analysis can be conducted by SEM, which is a test that has been utilized by previous models and theories.

\section{Sampling}

The sampling provides the definition of the target sample population. A sampling frame is a complete description of the elements of the samples taken to represent the population (Sekaran, 2003). Ideally, a sample of the framework meets all the elements in the population and the sample was taken as targeted by the investigation. In this study the samples taken from the Bureau of Planning and the Center for Data and Information of several ministries in Indonesia. Samples were taken from a man who used to be involved in the selection of information system projects. Data samples were obtained from as much as 294 respondents.

\section{Instrument Variables}

This study aims to look at and examine the direct relationship between technology and environment variables, and the dependent variable, effectiveness of information systems project selection and user acceptance as mediating variables. Additionally, also aims to examine the indirect relationship of technology and the environment variables with the dependent variable of success of information systems project selection through the mediating variables of user acceptance. Instrument for the variables are obvious from the theory. The technology consists of several items adopted from (Huang, Chu \& Chiang, 2008; Jiang \& Klein, 1999; Meade \& Presley, 2002) while environmental items were adopted from (Jiang \& Klein, 1999; Meade \& Presley, 2002). Moreover, user acceptance has several items adopted from (Davis, 1989), and perceived usefulness and perceived ease of use are used to gauge user acceptance. The effectiveness of the information systems project selection consists of several items, which are adopted from (Ghasemzadeh \& Archer,
2000; Hasan \& Ali, 2007; Wang, Xu \& Li, 2009).

\section{Analysis}

SEM analysis is conducted by constructing the measurement model and structural model. The measurement model analyzed the relationship between a set of observed variables and a predetermined number of latent variables. Reliability was tested using reliability and validity techniques. After ensuring that the scale is reliable, the next step is to examine the construct validity. Then the measurement model was evaluated and resolved before the structural model was performed. Data were analyzed using SPSS statistical software AMOS 14.0 and 16.0. Reliability coefficients (Cronbach's alpha values) obtained with each construct is as follows: technology $=0.814$, environment $=0.869$, user acceptance $=0.725$ and effectiveness of project selection information $=0.881$. Cronbach Alpha values are all greater than 0.725 indicating that all constructs are reliable.

\section{The Measurement Models}

After confirmatory factor analysis of each construct, the structural model is estimated including only the indicators that have been tested with confirmatory analysis. After modification, the indices are high value so no items are deleted. In a study to determine the model fit the item will be located at the end of the instrument. As a result, there are multiple variables with only a few items, and at least two items used to measure a variable (Palvia, 1999).

After the CFA (Confirmatory Factor Analysis) of the structural model, the overall fit indices for the proposed model is acceptable. The results of its goodness of fit was Che-square $(\mathrm{X} 2)=146.6, \mathrm{df}=125$, ratio X2 / df $=1.17$, probability $=0.91$, Root Mean Square Error of aproximation $($ RMSEA $)=0.026, \mathrm{GFI}=0.94, \mathrm{TLI}=0.98$, as presented in Table 1 . The model already meets the goodness of fit. 
Table 1. Summary of Model Fit Indices for CFA Model

\begin{tabular}{|lccccccc|}
\hline Model & $\mathrm{X}^{2}$ & $\mathrm{df}$ & $\mathrm{X}^{2} / \mathrm{df}$ & Prob GFI & TLI & RMSEA \\
\hline CFA & 146.6 & 125 & 1.17 & 0.91 & 0.94 & 0.98 & 0.026 \\
\hline
\end{tabular}

\section{Reliability}

Reliability is assessed at two levels: item reliability and construct reliability (Hair at al., 2010). The standardized loading for each item must be greater than 0.7 to indicate reliability, but a value of 0.50 is still acceptable (Hair at al., 2010; Nusair, 2010). Construct reliability refers to the degree that reflects that the observed instruments is a major factor. Construct reliability value of 0.7 is usually required and the minimum value of 0.5 is acceptable while item reliability between 0.725-0.869 indicates good item reliability and construct reliability values between 0.919 0.968 indicate high reliability. To measure the reliability of a construct, Construct Reliability (CR) is used with the formula (Hair at al., 2010; Nusair, 2010):

$\mathrm{CR}=(\Sigma \text { standard loading factor })^{2} /((\Sigma$ standard loading factor) ${ }^{2}+\sum \varepsilon j$ ).

\section{Description:}

a. Standard loading factor is taken of each item

b. $\varepsilon j$ is the error variance.

\section{Construct Validity}

The indicators of a construct can explain it through a process known as construct validity (Hair at al., 2010) [10]. For the purpose of the analysis, the process of construct validity can be conducted as follows:

\section{Convergent Validity}

Convergent validity determines whether each item is a valid measure of the construct (Hair at al., 2010). If indeed the item describes a construct then the item will have a high loading factor and will have a high Average variance extracted
(AVE). AVE value of less than 0.50 is not acceptable and more than 0.50 is amazing, and 0.70 is the ideal (Hair at al., 2010). The analysis showed that the AVE values are between 0.739-0.893 indicating a good result. AVE values can be seen in Table 2 . Value Average Variance Extracted (AVE) was calculated by the formula (Nusair, 2010):

AVE $=\Sigma$ (standardized loding factor $)^{2} /(\Sigma$ (standardized loading) ${ }^{2}+\sum \varepsilon j$ ).

Description:

a. Standard loading factor is taken of each item

b. $\varepsilon j$ is the error variance.

\section{Discriminant Validity}

Discriminant validity tool measures how far a totally different construct is from other constructs with each being an independent construct. Discriminant validity finds how two different constructs are more or less correlated. Discriminant validity testing is conducted on the constructs to see the independence of these constructs. Discriminant validity is calculated from the Average Variance Extracted (AVE) of a construct compared with the square of the correlation of the two constructs.

If the results are; AVE > of the squared correlation between two constructs, then each of the variables is not perfectly correlated or discriminant validity is achieved (Hair at al., 2010). The results of these analyses show AVE to be greater than the correlation between the two constructs, the AVE values are between 0.739-0.893 and 0.398-0.589 and hence showing the correlation between the constructs. These results can be seen in Table 2. 
Table 2. Discriminant Validity Matrix

\begin{tabular}{|lccll|}
\hline & TECH & ENV & USER & PS . \\
\hline TECH & $\mathbf{0 . 7 3 9}$ & & & \\
\hline ENV & 0.425 & $\mathbf{0 . 8 9 3}$ & & \\
\hline USER & 0.545 & 0.516 & $\mathbf{0 . 7 6 1}$ & \\
\hline PS & 0.469 & 0.398 & 0.589 & $\mathbf{0 . 8 5 9}$ \\
\hline
\end{tabular}

\section{The Results of Hypothesis}

By analyzing the results of the hypotheses, the researcher can analyze the strength of influence between variables (directly and indirectly). Direct influence is depicted by coefficient of all stripes with arrows on one end while the indirect effect is the effect that emerges through a mediating variable. The results of hypotheses 1 through 5 are all significant except hypothesis 2. The hypothesis results of direct effects can be seen in Table 3 . The results of hypothesis 6 postulates full mediating user acceptance of the technology upon the effectiveness of the information system project selection. Hypothesis 7 states that user acceptance fully mediates the effectiveness of the information system project selection. The results of hypotheses 1 through 5 can be seen in Table 3 and the results of hypotheses 6 and 7 can be seen in Table 4 .

Table 3. Result of Direct Effect

\begin{tabular}{|l|l|l|l|l|ll|}
\hline Hypothesis & \multicolumn{1}{|c|}{ Effect } & Estimate & S.E & CR & P & Hypo. Result \\
\hline $\mathrm{H}_{01}$ & TECH $\rightarrow$ PS & 0.606 & 0.265 & 2.289 & 0.022 & significant \\
$\mathrm{H}_{02}$ & ENV $\rightarrow$ PS & 0.090 & 0.078 & 1.149 & 0.251 & not signific. \\
$\mathrm{H}_{03}$ & USER $\rightarrow$ PS & 1.397 & 0.352 & 3.972 & 0.000 & significant \\
$\mathrm{H}_{04}$ & TECH $\rightarrow$ USER & 0.456 & 0.099 & 4.612 & 0.000 & significant \\
$\mathrm{H}_{05}$ & ENV $\rightarrow$ USER & 0.139 & 0.031 & 4.494 & 0.000 & significant \\
\hline
\end{tabular}

Table 4. Result of Indirect Effect

\begin{tabular}{|c|c|c|c|c|}
\hline Hypothesis & $\begin{array}{ll}\text { Exogen } & \text { Mediating } \\
\text { Endogen } & \end{array}$ & $\begin{array}{l}\text { Direct } \\
\text { effect }\end{array}$ & $\begin{array}{l}\text { Indirect } \\
\text { effect }\end{array}$ & $\begin{array}{l}\text { Hypothesis } \\
\text { result }\end{array}$ \\
\hline $\begin{array}{l}\mathrm{H}_{06} \\
\mathrm{H}_{07}\end{array}$ & $\begin{array}{l}\text { TECH } \rightarrow \text { USER } \underset{\text { (Sig.) }}{\rightarrow} \text { (Sig.) } \\
\text { ENV } \underset{\text { (Sig.) }}{\rightarrow} \text { USER } \underset{(\text { Sig. })}{\rightarrow} \text { PS }\end{array}$ & $\begin{array}{l}0.233 \\
0.100\end{array}$ & $\begin{array}{l}0.245 \\
0.217\end{array}$ & $\begin{array}{l}\text { Full } \\
\text { Mediating } \\
\text { Full } \\
\text { Mediating }\end{array}$ \\
\hline
\end{tabular}

\section{Discussion}

The results can be discussed following the hypothesis. The hypothesis stating that technology significantly affects the information systems project selection (hypothesis 1) was tested. This decision is in accordance with (Yap et al., 1992; Vargas etal., 2003; Wei at al., 2007). Yap et al. (1992) examines technology in enterprise information systems in a study using SMART technology and the results show that technology affects information system project selection. Apparently, technology is very influential upon the information system project. The technology is easy to use and reliable as needed. Furthermore, Vargas (2003) reviewed the implementation of the technology in Spanish pharmaceutical company in the system used for sales orders and uses the integrated system. The result reveals that the company's operations make use of the system in a way that the latter makes the pharmaceutical company effective. Wei (2007) examined the integration of large amounts of information systems to support business-wide business initiatives such as 
e-business, chain management and customer communications management. In the current times, most organizations have tended to use the information systems integration. However, some organizations are now adopting a more strategic and systematic method for integrated information systems. With this integration, the success of business initiatives is realized and technology in businesses has become an increasingly important consideration in the selection of projects. In fact, many employees use computers to complete their work. For future, computer technology will evolve and the project should adjust to these technological developments.

The results of the test of hypothesis 2 reveal that environment does not directly affect the selection of information system project which is contrary to (Wei et al., 2007; Chen \& Cheng, 2009; Wang et al., 2009). In Wei's (2007) study of the effect of environment on project selection, the environment is highly considered in making the decision. In addition, environmental decision-making should be kept in mind when laying down the strategy objectives. Because of the many variables that influence the selection of information system project, the possibility of other variables that influence it exists. In fact, the environment is very important for project information.

In other studies, the environment was found to not directly influence the effectiveness of the information systems project selection but the influence is through the mediating role of user acceptance (hypothesis 7). This decision is in accordance with (Igbaria et al., 1995; Venkatesh \& Davis, 2000). Igbaria et al. (1997), in her study of personal computing acceptance factors in small firms in New Zealand, found that external variables affect project information by the mediating affect of user acceptance. In addition, Vakantesh \& Davis (2000) also revealed the mediating role of user acceptance of information technology to the project selection. Generally, the environment largely determines the information systems project. If the environment does not support the project, it may not run properly. However, it does not directly affect the effectiveness of the information systems project selection but indirectly influences it through mediating user acceptance. The neighborhood here is the internal and external environment. In building project, if the external information system objected to any information system project then the project can be closed. Internal environment involves organizational and human resources. If the organization and human resources do not support the project, it will be terminated. And it turns out the internal and external environment is very influential in the selection of information system projects.

The postulation of user acceptance variable significantly impacting the effectiveness of the information systems project selection (hypothesis 3) is based in accordance with (Ghobakhloo, 2010; Youngberg et al., 2009; Zhou, 2008). In Ghobakhloo's (2010) study regarding the effectiveness of the related user acceptance of information systems project selection in small and medium businesses, it was revealed that project implementation should consider user acceptance information. Furthermore, Zhou (2008) investigated the use of mobile phones used to spread entertainment community. He revealed that user acceptance of information systems affect project selection of the public dissemination of mobile entertainment. Also, Youngberg's (2009) study on user acceptance of the technology in a private company revealed that users acceptance and use of technology lead to the company's successes. Hence, user acceptance is an important factor in the selection of project. If the project is run and the user fails to understand its purpose then the project will fail. In other words, a project that cannot be understood and used by the user should not continue.

Hypothesis 4 postulates that technology affects user acceptance; a hypothesis that is supported by (Ghobakhloo, 2010; Wang et al., 2009). User acceptance was tested through the incorporation of usefulness and ease of use and it revealed very significant results and goodness of fit. So 
the incorporation of usefulness and ease of use makes it easier and simpler for the researcher to examine the hypothesis. Ghobakhloo (2010), in his research on user acceptance of technology in small and medium enterprises (SMEs), showed that user acceptance, in small and medium businesses, is affected by technology. Moreover, Wang (2009) examined the entertainment communities via mobile phones in China. The result showed that the technology and service quality influence user acceptance indicating that existing technologies that are easy to use gets the job done. It is important that technology users can use the technology and complete their tasks with it. In fact, any new information system project should consider users. If users understand and can use the new projects and are satisfied with it, then the project can be implemented. Reliable technology is expected to complete the ministry's work. A simple module will be preferred by the users for easy understanding. Besides, easily understood modules are usually simple and easy to implement. If users are satisfied with using the system, information technology is suitable for the job. Information technology systems that can accomplish a lot of work are usually preferred by the user. An information system should be made to adjust to user needs. The information system used should be able to complete all types of tasks. The system should be an integrated system, which usually involves the contribution of professional users.

Hypothesis 5 postulates that the environment directly impacts user acceptance which is in accordance with (Ghobakhloo, 2010; Yap et al., 1992; Youngberg et al., 2009). Yap (1992), in her study of user acceptance in the design of enterprise resource (ERP) in China, revealed that family or friends and even work environment greatly affects user acceptance. Moreover, Youngberg (2009) examined the use of technology in an enterprise environment and the findings showed that the organizational environment affects the use of technology for the company's success. Additionally Ghobakhloo (2010), in her study of user acceptance technology on small and medium enterprises (SMEs), revealed that user acceptance is influenced by the environment. In addition, user acceptance and user satisfaction should be considered as they affect the success of the use of technology in small and medium businesses. Understanding user acceptance of information technology and user satisfaction in the SMEs is important with a special focus on the environment and the interactions required between individuals within and outside the organization. In a good environment, employees will welcome the use of technology. Besides, a technological environment that is easy to learn and is flexible will be accepted by the user.

The results of hypothesis 6 support user acceptance as mediating variable. This means that the impact of technology indirectly influences the effectiveness of the information systems project selection if they pay attention to user acceptance. Turns out merging conveniences usability testing and use of the results are very fit and simpler. If the user accepts and can use the information project then the project will be implemented. If the user does not receive or cannot use, then the project is likely not selected. Igbaria (1997) examined the factors of acceptance of personal computers in a small company in New Zealand. He said that external factors affect project information through the mediating effect of user acceptance. Similarly, Davis (1989) stated that users act as a mediating variable external to information behavior. User acceptance is measured through perceived usefulness and perceived ease of use. It has been advised that for high reliability, perceived usefulness and perceived ease of use should not be mixed. However, the results of this study of perceived usefulness and ease of use are mixed but it is not biased as it provides a more reliable, simpler and easier to understand outcome.

User acceptance of technology fully mediates the effectiveness of the information system project selection. This is because the direct influence of technology directly upon effectiveness of 
project selection is lower compared to its indirect influence through user acceptance. This means that the technology affects the effectiveness of the information systems project selection through the mediating role of user acceptance.

\section{Conclusion}

From the description above, the following points can be summarized:

1. Measuring user acceptance through the incorporation of usefulness and ease of use makes for simple and suitable results. This study does not diminish the results of previous studies concerning user acceptance in its attempt to conduct simple measurement of user acceptance.

2. Technology and user acceptance directly influence information systems project selection resulting in a more effective and efficient project.

3. In this study, technological and environmental factors significantly and directly affect the user's reception.

4. Technology does not directly affect the effectiveness of information systems project selection through the mediation of user acceptance, and user acceptance in this study as a full mediating.

5. Environment indirectly affects the effectiveness of the information systems project selection through the mediating effect of user acceptance. It turns out the external environment is very influential on the selection of projects and information systems; a finding which is a primary contribution of the present research.

\section{References}

Bowman, R. A. (2006). "Discrete Optimization Developing Activity Duration Specification Limits for Effective Project Control," European Journal of Operational Research, 174, 1191-1204.
Buchanan, J. \& Vanderpooten, D. (2007). "Ranking Projects For An Electricity Utility Using Electre III," International Transactions in Operational Research, 14, (4), 309-323.

Chen, C. T. \& Cheng, H. L. (2009). "A Comprehensive Model for Selecting Information System Project Under Fuzzy Environment," International Journal of Project Management, 27,389-399.

Cohen, S. G. \& Bailey, D. E. (1997). "What Makes Teams Work: Group Effectiveness Research from the Shop Floor to the Executive Suite," Journal of Management, Vol 23, 234-290.

Davis, F. D. (1989). "Perceived Usefulness, Perceived Ease of Use, and User Acceptance of Information Technology," MIS Quarterly, 13, (3), 319-340.

Fedor, D. B., Ghosh, S., Caldwell, S. D., Maurer, T. J. \& Singhal, V. R. (2003). "The Effects of Knowledge Management on Team Members' Ratings of Project Success and Impact," Decision Sciences Volume 34 Number 3.

Ghasemzadeh, F. \& Archer, N. P. (2000). "Project Portofolio Selection through Decision Support," Decision Support System, 29, (73-88).

Ghobakhloo, M., Zulkifli, N. B. \& Aziz, F. A. (2010). 'The Interactive Model of User Information Technology Acceptance and Satisfaction in Small and Medium-sized Enterprises,' European Journal of Economics, Finance and Administrative Sciences, 19, 7-27.

Hair, J. F., Black, W. C., Babin, B. J. \& Anderson, R. E. (2010). 'Multivariate Data Analysis a Global Perspective,' Pearson Prentice Hall USA.

Hasan, B. \& Ali, J. (2007). "An Empirical Examination of Factors Affecting Group Effectiveness in Information System Projects," Decision Sciences Journal of Innovative Education 5(2): 229-243. 
Huang, C. C., Chu, P. Y. \& Chiang, Y. H. (2008). "A Fuzzy AHP Application in Government-Sponsored R\&D Project Selection," Omega. 36: 1038-1052.

Igbaria, M., Guimaraes, T. \& Davis, G. B. (1995). "Testing the Determinants of Microcomputer Usage via a Structural Equation Model," Journal of Management Information Systems, 11 (4), 87-114.

Jiang, J. J. \& Klein, G. (1999). "Research Project Selection Criteria By Strategic Orientation," Information \& Management, 36, 63-75.

Jiang, J. J., Klein, G. \& Carr, C. L. (2002). "Measuring Information System Service Quality: Servqual from the Other," MIS Quarterly Vol. 26 No. 2, pp. 145-166.

Lam, W. (2010). 'Teaching Case Information Systems Integration and Enterprise Application Integration (EAI) Adoption: A Case from Financial Services,' Journal of Information Systems Education, Vol. 18(2).

Meade, L. M. \& Presley, A. (2002)."R\&D Project Selection Using the Analytic Network Process," IEEE Transactions on Engineering Management 49(1): 8.

Nusair, K. \& Hua, N. (2010). "Comparative Assessment of Structural Equation Modeling and Multiple Regression Research Methodologies: E-Commerce Context," Tourism Management 31 (2010) 314-324

Palvia, P. C. \& Palvia, S. C. (1999). "Research an Examination of the IT Satisfaction of Small-Business Users," Information \& Management 35 (1999) 127-137.

Puthamont, S. \& Charoenngen, C. (2007). "Strategic Project Selection in Public Sector: Construction Project of the Ministry of Defense in Thailand," International Journal of Project Management. 25 (2007) 178-188.

Rosacker, K. M. \& Olson, D. L. (2008). “An Empirical Assessment of IT Project Selection and Evaluation Methods in State
Government," Project Management Journal,39, 49-58.

Sekaran, U. (2003). 'Research Method for Business A Skill Building Approach, Fourht Internet Advertising,' 4th Edition. Singapore: John Wiley \& Son Inc.

Vargas, A., Hernandez, M. J. \& Bruque, S. (2003). "Determinants of Information Technology Competitive Value, Evidence From A Western European Industry," Journal of High Technology Management Research, 14, 245-268.

Venkatesh, V. \& Davis, F. D. (2000). "A Theoretical Extension of the Technology Acceptance Model: Four Longitudinal Field Studies," Management Science, 46 (2), 186204.

Wang, J., Xu, Y. \& Li, Z. (2009). "Research on Project Selection System of Pre-Evaluation of Engineering Design Project Bidding," International Journal of Project Management, 27, 584-599.

Wei, C. C., Liang, G. S. \& Wang, M. J. J. (2007). "A Comprehensive Supply Chain Management Project Selection Framework under Fuzzy Environment," International Journal of Project Management, 25, 627636.

Yan, X., Gong, M. \& Thong, J. Y. L. (2006). "Two Tales of One Service: User Acceptance of Short Message Service (SMS) in Hong Kong and China," Info, Vol. 8, NO. 1, 16-28, Emerald Group Publishing.

Yap, C. S., Ram, K. S. \& Leong, C. M. (1992). "Methods for Information System Project Selection: An Experimental Study of AHP and SMART," Proceedings of the TwentyFifth Hawaii International Conference on System Sciences, 1992.

Yoon, C. Y. (2009). "Measures of Perceived End-User Computing Competency in an Organizational Computing Environment," Knowledge-Based Systems, 22, 471-476.

Youngberg, E., Olsenb, D. \& Hauser, K. (2009). "Determinants of Professionally Autonomous end User Acceptance in an 
13 Journal of Southeast Asian Research

Enterprise Resource Planning System Environment," International Journal of Information Management 29 (2009) 138144.

Zhang, J., Ghorbani, A. A. \& Cohen, R. (2007). "A Familiarity-Based Trust Model for Effective Selection of Sellers in Multiagent E-Commerce Systems," International Journal Information Security (2007) 6:333-344.

Zhou, T. (2008). "The Impact of Perceived Value on User Acceptance of Mobile Commerce," International Symposium on Electronic Commerce and Security. 